\title{
Design and Development of a High Efficiency Air Turbine Spindle for Small-Part Machining
}

\author{
Paul Harris $^{1} \cdot$ Michael Wintterer $^{2} \cdot$ David Jasper $^{2} \cdot$ Barbara Linke $^{3} \cdot$ Christian Brecher $^{2} \cdot$ Stephen Spence ${ }^{1}$
}

Received: 14 March 2018 / Revised: 28 August 2018 / Accepted: 4 September 2018 / Published online: 7 June 2019

(c) The Author(s) 2019

\begin{abstract}
This paper reports on the development of a high efficiency and low inertia miniature pneumatic turbine for ultra-high-speed manufacturing spindle applications. It is proposed that radial-inflow/axial-outflow type turbines are well suited for micromachining spindles. To validate the turbine performance potential, a proof-of-concept prototype turbo-spindle was developed and experimentally tested. The prototype spindle produced a net mechanical power output of over $60 \mathrm{~W}$ at a speed of $90,000 \mathrm{rpm}$. The experimental results demonstrate a micro-turbine efficiency of over 50\% and a turbine power output of approximately $100 \mathrm{~W}$. This compares to a typical turbine efficiency of around $20 \%$ in commercial micro-machining spindles. Further potential improvements to both turbine and spindle energy efficiency are outlined.
\end{abstract}

Keywords Energy efficiency $\cdot$ Micro-machining $\cdot$ Spindle $\cdot$ Turbine

\section{List of symbols}

$\begin{array}{ll}\text { A } & \text { Flow area }\left(\mathrm{m}^{2}\right) \\ \mathrm{b} & \text { Blade span/height }(\mathrm{m}) \\ \mathrm{C}_{\mathrm{p}} & \text { Specific heat at constant pressure }(\mathrm{J} / \mathrm{kg} \mathrm{K}) \\ \mathrm{m} & \text { Mass flow rate }(\mathrm{kg} / \mathrm{s}) \\ \mathrm{P} & \text { Pressure }(\mathrm{Pa}) \\ \mathrm{Pw} & \text { Power }(\mathrm{W}) \\ \mathrm{Q} & \text { Cooling capacity }(\mathrm{W}) \\ \mathrm{r} & \text { Radius }(\mathrm{m}) \\ \mathrm{T} & \text { Temperature }(\mathrm{K}) \\ \mathrm{U} & \text { Blade speed }(\mathrm{m} / \mathrm{s}) \\ \mathrm{V} & \text { Absolute flow velocity }(\mathrm{m} / \mathrm{s}) \\ \mathrm{V} & \text { Volumetric flow rate }\left(\mathrm{m}^{3} / \mathrm{s}\right) \\ \mathrm{W} & \text { Relative flow velocity }(\mathrm{m} / \mathrm{s}) \\ \varepsilon & \text { Clearance }(\mathrm{m}) \\ \eta & \text { Efficiency }(\%) \\ \tau & \text { Torque }(\mathrm{Nm})\end{array}$

Stephen Spence

S.W.Spence@qub.ac.uk

1 School of Mechanical and Aerospace Engineering, Queen's University Belfast, Belfast, UK

2 Laboratory for Machine Tools and Production Engineering (WZL), RWTH Aachen University, Aachen, Germany

3 Department of Mechanical and Aerospace Engineering, University of California at Davis, Davis, USA

\author{
Subscripts \\ a Atmospheric conditions \\ h Hub \\ $\mathrm{r} \quad$ Radial direction \\ $\mathrm{t} \quad$ Tip \\ u Upstream \\ $\mathrm{x} \quad$ Axial direction \\ 4 Turbine rotor inlet \\ 6 Turbine rotor outlet \\ Abbreviations \\ BLDC Brushless direct current \\ CFD Computational fluid dynamics \\ FEM Finite element model/method \\ F.S. Full scale \\ m.v. Measured value \\ NGV Nozzle guide vanes \\ PWM Pulse width modulation \\ SMA Shape memory alloy \\ TIR Total indicated run-out \\ UHS Ultra-high speed
}

\section{Introduction}

For mechanical micro-machining with $10 \mu \mathrm{m}$ to $1 \mathrm{~mm}$ sized cutting tools, there is a requirement for spindles to operate at rotational speeds in excess of 100,000 rpm for both productivity and quality reasons. Pneumatic turbine drive 
technology is often employed for such applications for its advantages in terms of speed capability, lack of heat generation, small size and weight, and robustness. Air turbine spindles are particularly prevalent for ultra-precision machine tools, desktop machine tools e.g. see Fig. 1, and as insertable units ("spindle speeders") to upgrade the speed capability of conventional machine tools [1].

Much of the research on ultra-high speed (UHS) spindles to date has focused on achieving higher speeds with greater precision. $\mathrm{Li}$ et al. [2, 3] proposed a spindle for micro mechanical machining with a monolithic flexible coupling, to decouple the tool from the shaft/drive, and a Shape Memory Alloy (SMA) toolholder. Their prototype (turbine driven) spindle achieved a maximum speed of $240,000 \mathrm{rpm}$ and radial run-out of $2.79 \mu \mathrm{m}$. Sung [4] developed a (turbine driven) spindle with a 422,000 rpm maximum speed and radial run-out of $3.2 \mu \mathrm{m}$. Jahanmir et al. [5] developed a prototype UHS spindle with turbine drive for micro-milling with rotational speeds up to 450,000 rpm. The authors demonstrated an order of magnitude increase in the material removal rate in comparison to a $60,000 \mathrm{rpm}$ baseline machining case. Aurich et al. [6] proposed a novel approach whereby a micro-tool shank is used as the spindle rotor and thus a functional part of the (air) bearing system. The drive turbine is thus mounted directly on the tool-rotor. The developed prototype UHS spindle reached a maximum rotational speed of approximately 220,000 rpm with a runout of $0.7 \mu \mathrm{m}$. Park et al. developed and demonstrated a (turbine driven) miniature spindle with a combination of active magnetic bearings and aerostatic bearings for operation up to 200,000 rpm [7]. Their hybrid bearing spindle featured active control of tool orbit during rotation. Such active control approaches may allow for the generation of micro patterns and textured surfaces in the future [7]. Knapp and Arneson [8] demonstrated an ultra-precision air bearing electro-spindle with total radial and axial error motions of less than $25 \mathrm{~nm}$ at 50,000 rpm. To achieve such nanometerlevel error motions balancing was critical. A balance grade of better than G0.1 was achieved using weight corrections on the order of micrograms [8].

Furthermore, given that effective micromachining requires a high level of dimensional accuracy, form accuracy

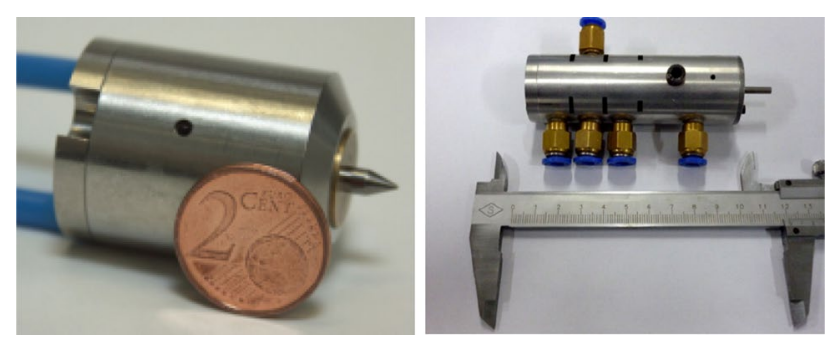

Fig. 1 Example turbo-spindles for micro-machining [2, 5] and surface finish, spindle error motions have been studied extensively by a number of authors. Creighton et al. [9] investigated the thermal induced errors due to bearing heat generation and developed a growth compensation scheme for micro-milling type spindles. Anandan et al. [10] investigated the radial and axial motions of a miniature (electrically driven) UHS spindle with hybrid ball bearings, in particular the influence of temperature fluctuations, dynamic (vibration) effects, contact bearing defects and tool-attachment errors. Bediz et al. [11] examined the dynamics of a rotating UHS spindle with air bearings using a custom designed impact excitation system. Zhang et Ehmann [12] developed a design methodology for air bearing micro-spindles with a focus on controlling runout. Shin et al. [13] developed a shape memory alloy clamp for micro tools to reduce tolerance stackup (associated with traditional collet toolholders) whilst only requiring a relatively small temperature differential to change between clamp and unclamp states. The referenced papers focus on the spindle's bearing design, tool holder concepts, motion error quantification and compensation etc.

The emphasis in this work is on improving turbine spindle ('turbo-spindle') performance in terms of efficiency, power density and time-to-speed i.e. the time to accelerate to cutting speed. The pneumatic turbine design is a key determinant of the spindle's efficiency, size, weight, and rotor inertia. Improving turbine efficiency reduces the cost of spindle ownership and environmental impact (through reduced energy usage) and/or increases the available power output. This in turn can improve the spindle's speed range, power-to-weight ratio and time-to-speed (acceleration) capabilities. Increased productivity in the machining process also reduces environmental impact in terms of energy consumed per unit/workpiece. Current commercial turbo-spindles suffer from low energy efficiency in the range of 10-20\% [14]. The technical challenge is to simultaneously achieve a high efficiency, low inertia, low weight, and compact spindle which also meets micro-machining spindle requirements. Only a limited number of researchers have focused on the turbine design for micromachining spindles. Jackson et al. [15] simulated air turbine spindles with speeds up to 5 million rpm using CFD software, though experimentally tested speeds were much lower. Muller et al. [16] designed and optimised a $10 \mathrm{~W}$ micro-turbine for a target operational speed of 300,000 rpm. In terms of the turbine design, the authors employed a tangential flow (impulse) type turbine, though the power output and efficiency of the turbine were not investigated experimentally. An innovative viscous driven turbine concept (i.e. bladeless turbine) was proposed by Delhaes et al. [17] for micro-millling, with the advantage that the (air) bearing and drive functions are combined into one machine component. However, the prototype spindle only reached a maximum speed of $24,000 \mathrm{rpm}$. 
Table 1 Spindle and turbine design specifications

\begin{tabular}{|c|c|c|}
\hline Speed $^{\mathrm{a}}$ & $\mathrm{rpm}$ & 100,000 \\
\hline Torque $^{\mathrm{a}}$, turbine/spindle & $\mathrm{m} \mathrm{Nm}$ & $11 / 7$ \\
\hline Power output ${ }^{\mathrm{a}}$, turbine/spindle & $\mathrm{W}$ & $120 / 80$ \\
\hline Axial stiffness & $\mathrm{N} / \mu \mathrm{m}$ & 10 \\
\hline TIR & $\mu \mathrm{m}$ & 3 \\
\hline
\end{tabular}

${ }^{\mathrm{a}}$ Nominal

In this paper, the design, development, and testing, of a new turbo-spindle concept for micro-machining is presented. The spindle employs a radial-inflow/axial-outflow turbine for high efficiency actuation. A radial turbine type design is preferred due to the small geometric size, low mass flow, relatively low rotational speed and high pressure (i.e. low specific speed) conditions required of micro-machining turbo-spindles. The specifications for the turbo-spindle are shown in Table 1 . The cutting torque and speed requirements for a micro-milling spindle were calculated based on a range of end mill tool diameters from $100 \mu \mathrm{m}$ to $2 \mathrm{~mm}$. The expected workpiece materials included aluminium, steel, and copper alloys. In addition to cutting power, the additional power requirements to overcome internal frictional losses were also considered for the motor. Note, the power output of the spindle is less than the turbine due to these internal losses (Table 1). The spindle was to be mounted horizontally. The typical total indicated runout (TIR) of commercial turbo-spindles, is measured at the nose of the spindle, and ranges from 1 to $5 \mu \mathrm{m}$ [6]. Therefore, the target TIR for the prototype spindle was set to be in this range. The intended speed range of the spindle was 50,000-150,000 rpm, with a nominal design speed of 100,000 rpm (Table 1).

\section{Turbo-Spindle Design, Simulation and Analysis}

\subsection{Rotor and Spindle Structure}

To keep the spindle design simple and costs low, the prototype employed angular contact ball bearings. The radial and axial cutting forces in micromachining are generally quite small, i.e. less than $1 \mathrm{~N}$. The static gravity load (in the radial direction for a horizontally mounted spindle) on the prototype was also found to be negligible. The main expected loads on the spindle were due to the bearing preload, especially at higher speed, and turbine rotor thrust, both of which act in the axial direction. Such axial forces are difficult to predict with accuracy a priori without established empirical data. The overall structure of the spindle rotor assembly is shown in Fig. 2 and consists of a duplex back-to-back pair of angular contact ball bearings at the front/tool-end and back/

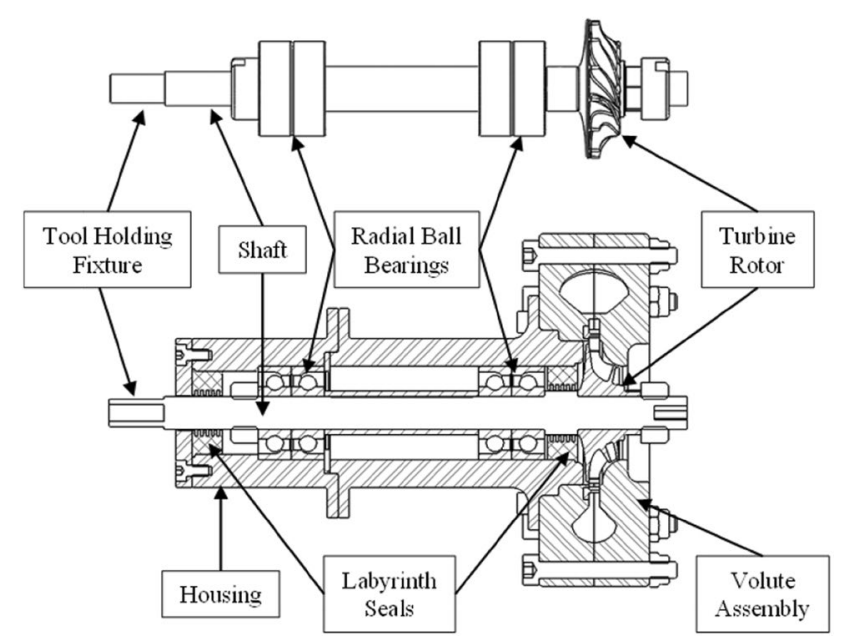

Fig. 2 Turbo-spindle rotor assembly (top) and cross-section of complete prototype (bottom)

turbine-end of the spindle respectively. The bearing span was $40 \mathrm{~mm}$. The turbine rotor was overhung to allow for a compact design and ease of assembly. In addition, the turbine exhausted to the rear of the spindle to avoid significant airflow through the ball bearings.

State-of-the-art hybrid angular contact ball bearings, with Cronidur steel rings and ceramic balls, allow for angular speeds of up to $190,000 \mathrm{rpm}$ (DN 1140,000) and $280,000 \mathrm{rpm}$ (DN 1680,000) with grease and oil-air lubrication respectively. These values are for single bearings, and attainable speed is reduced with duplex sets. The selected ball bearings (SKF $706 \mathrm{CE}$ ) had a $6 \mathrm{~mm}$ bore, $15^{\circ}$ contact angle and an axial stiffness in the range of 9-18 N/ $\mu \mathrm{m}$, depending on preload. The radial stiffness of the ball bearings was not provided in the datasheets but is typically three-to-four times the axial stiffness for bearings with a $15^{\circ}$ contact angle [18]. The dynamic and static load ratings of the selected bearings were $1.5 \mathrm{kN}$ and $0.5 \mathrm{kN}$, respectively. A fixed bearing preload was chosen to improve the rigidity of the system. The matched bearings at both ends were axially preloaded by mounting adjacent to each other, with the preload predetermined by the manufacturer. A light preload of approximately $10 \mathrm{~N}$ was selected, as it was expected that the preload would increase significantly at high speed. The duplex pair of bearings at the front of the spindle were axially located (fixed) to allow for thrust loads in both directions. The rear bearing pair were floating (non-locating) to compensate for thermal expansion at high speed. Locknuts were used for clamping both the turbine and front bearing on the rotor assembly.

For the initial prototype, grease lubrication was employed (SKF LGLT2) for the bearings. The recommended grease quantity was miniscule $(0.03 \mathrm{~mL})$. It is important to note that to attain the intended high speed with rolling contact 
type bearings requires the use of a small diameter shaft. This implies a relatively low stiffness of the shaft in comparison to the bearings. In fact, the $6 \mathrm{~mm}$ shaft diameter significantly reduced the overall radial stiffness of the system i.e. to less than $1 \mathrm{~N} / \mu \mathrm{m}$ at the toolholder.

There was no damping in the prototype turbo-spindle design except that due to internal damping in the bearings, which is normally minimal. A rotordynamic analysis was conducted using FEM (in ANSYS Mechanical) to estimate the natural frequencies of the rotor assembly and produce a Campbell diagram. However, the results need to be interpreted in light of the uncertainty regarding the bearing stiffness, which is not provided by the manufacturer and varies with speed and load. Likewise, the simplified single degree of freedom spring damper based engineering formulae provide a large range of first mode natural frequencies based on the (distributed) mass and stiffness assumptions for the rotor assembly.

\subsection{Turbine Stage}

The rotational speed and power output requirements for the turbine are dictated by the micro-machining process. Inlet pressure is the only adjustable parameter open to micromachining turbo-spindle designers. The upper supply pressure limit is determined by the factory/machine shop compressed air system. Typical industrial air compressors operate with an outlet pressure of 6-8 bar, though many manufacturing facilities also utilise lower pressure distributed or centralised compressors e.g. for pneumatic conveying applications. The lower limit for the turbine/spindle supply pressure is governed by tubing and flow channel sizing considerations. The sensitivity of a typical pneumatic pressure regulator is $0.5 \%$ of full span e.g. 0.04 bar resolution for 8 bar range. However, the effective control resolution is limited if using standard (Bourdon tube) gauges to around 0.1 bar. The design strategy taken in this project was to utilise as low an inlet pressure as possible whilst keeping the spindle size of similar dimension to existing commercial turbo-spindles. This inlet pressure was determined to be around $1.7 \mathrm{bar}$ at the design point $(100 \mathrm{~W}$ power output at $100,000 \mathrm{rpm})$. Even with the relatively low inlet pressure, the specific speed parameter is still well below optimal for a radial-inflow/axial-outflow turbine [19]. This is because the rotational speed of the spindle, whilst considered high from a machining perspective, is still too low to fully maximise turbine efficiency without significantly increasing the size of the turbine and spindle.

Some earlier turbine design variants for a micro-machining spindle, and their numerical simulations, were discussed in [20]. It was decided to increase the stage loading (from earlier designs) to further reduce potential thrust forces from the turbine and the housing diameter size. The higher stage
Table 2 Final turbine stage design parameters for prototype

\begin{tabular}{ll}
\hline Stage & \\
\hline Specific speed (rad) & 0.2 \\
Stage reaction & 0.24 \\
Work coefficient & 1.5 \\
Flow coefficient & 0.19 \\
Pressure ratio & 1.68 \\
Mass flow (g/s) & 4 \\
Radial interspace (mm) & 1.5 \\
Stator (Nozzle guide vanes) & \\
$\quad$ Aspect ratio & 0.21 \\
Solidity & 1.08 \\
Number of blades & 10 \\
Rotor & \\
Solidity (mid-span) & 3.13 \\
Number of blades & 13 \\
Rotational speed (rpm) & 100,000 \\
\hline
\end{tabular}
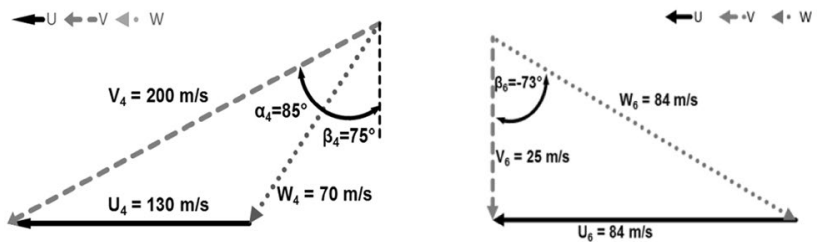

Fig. 3 Turbine rotor velocity triangles at design point, for inlet (left), and outlet tip (right)

loading also resulted in an increased inlet span to diameter ratio, which reduced the relative casing clearance at the rotor inlet. This design approach was a compromise between reducing turbine leakage losses, and the sensitivity of the turbine efficiency to clearance, at the expense of increasing rotor frictional losses. The final turbine variant geometric and aero-thermodynamic design parameters, and velocity triangles, are shown in Table 2 and Fig. 3, respectively. It is clear from the turbine rotor velocity triangles shown in Fig. 3 that the flow velocity is well below the speed of sound at the design point. The low reaction design resulted in an outlet flow angle from the Nozzle Guide Vane's (NGV's) of $85^{\circ}$, which is quite high in comparison to conventional radial turbines. To simplify manufacture, a $0^{\circ}$ rotor blade inlet angle was used i.e. purely radially fibred blade with no sweep. The resulting blade speed ratio was only 0.45 at the design point, which is well below the optimal ratio of approximately 0.7 for radial-inflow/axial-outflow turbines [19]. Figure 3 shows that the low blade speed causes significant positive incidence at the rotor inlet, which will likely cause flow separation on the blade suction surfaces [19].

CFD simulations with ANSYS CFX were used to determine a number of turbine blade design variables, including: 
pitch-to-chord length ratio, rotor blade deflection, minimum vane thickness and airfoil shape, leading and trailing edge elliptic ratios etc. Due to the low reaction turbine design and its operation at 'cold' (i.e. ambient) temperatures, the expected mechanical and thermal loads acting on the turbine rotor were relatively low. This facilitated the selection of low density metals, such as aluminium and magnesium alloys, for the rotor and helped to minimise the overall rotor moment of inertia. The turbine rotor was designed for a maximum operational speed of $170,000 \mathrm{rpm}$. At this speed, the maximum deformation of the rotor blades due to centrifugal force, was predicted to be under $10 \mu \mathrm{m}$ using a FEM simulation (ANSYS Mechanical). The maximum stress on the rotor was ensured to be less than the material yield stress with an appropriate safety factor. The predicted first mode natural frequency of the individual turbine rotor was $51 \mathrm{kHz}$ which was far above the maximum operating speed of the spindle.

\subsection{Volute}

The function of the volute is to distribute the flow around the periphery of the turbine to provide a uniform mass flowrate and uniform static pressure at the volute exit [19]. To achieve uniform exit conditions, the ratio of flow area to centroid radius $(A / r)$ must decrease linearly for each section. Several volute casing designs, with different centroid radii, were assessed using CFD simulations in ANSYS CFX. The final volute design is shown in Fig. 4 and has an outlet width and radius of $2 \mathrm{~mm}$ and $16 \mathrm{~mm}$, respectively. A single-entry volute with a symmetric cross-sectional area, comprising of a trapezoid with semi-ellipse, was chosen for simplicity. The volute inlet flow area was circular with a diameter of $10 \mathrm{~mm}$ and an $A / r$ ratio of 3.65. A CFD simulation analysis of the volute predicted an average flow velocity and outlet angle (measured from radial direction) of $35 \mathrm{~m} / \mathrm{s}$ and $71^{\circ}$, respectively at the design point (Fig. 5), and a total pressure loss of $292 \mathrm{~Pa}$.

Finally, the inlet fitting (push-in tube-to-thread adapter) and tubing was sized for a maximum air flow velocity of $30 \mathrm{~m} / \mathrm{s}$ at design conditions. Off-the-shelf pneumatic
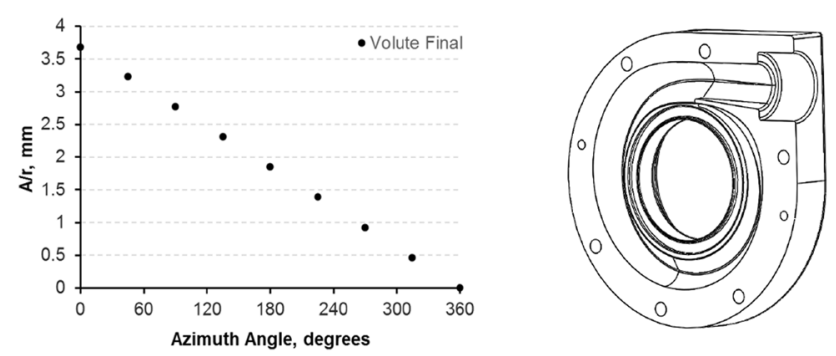

Fig. 4 Variation of volute $\mathrm{A} / \mathrm{r}$ ratio with azimuth angle and 3D CAD model of half-section
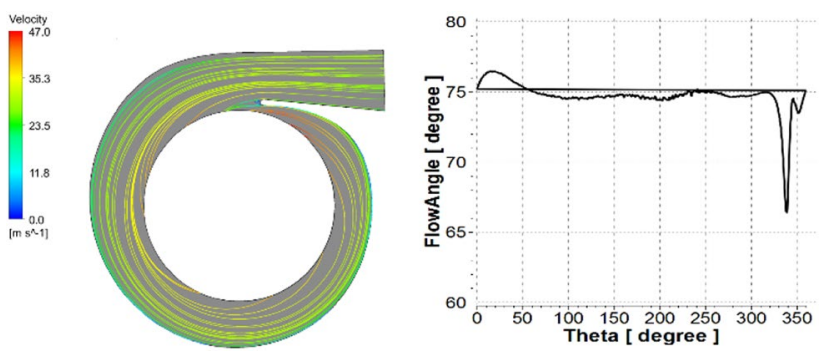

Fig. 5 CFD computed streamlines and flow velocity in volute (left), and outlet flow angles at 50\% span (right)

components were used to connect the turbo-spindle to a compressed air system e.g. $12 \mathrm{~mm}$ O.D. nylon tubing.

\subsection{Toolholder}

A shape memory alloy (SMA) based tool-holder design was initially considered due its specific advantages for clamping micro-tooling [13], but not pursued further due to lack of suitable off-the-shelf part availability. While nickel-titanium SMA rings were available commercially in the approximate size range, they required loosening temperatures of $-120^{\circ} \mathrm{C}$ which was deemed impractical for tool clamping purposes. The majority of SMA rings reported in the research literature were custom made/trained with a typical required cooling temperature for unclamping of just under $0{ }^{\circ} \mathrm{C}$ [13].

Instead a shrink fit approach was taken with direct clamping of the tool in the shaft. This also eliminates tolerance stack-up with the tool-holder, though with the trade-off of longer tool change times. However, to allow for clamping/ release of carbide micro-tools on the initial prototype using available resources (i.e. a heat gun) required the use of a shaft material with higher thermal coefficient of expansion. For this prototype a stainless steel (ANSI 316) was therefore selected as the shaft material, with the expectation of increased spindle motion errors due to thermal expansion. It is intended that the current stainless steel shaft will be replaced with a conventional hardened spindle steel in the future.

\subsection{Labyrinth Seals}

Due to the very high rotational speeds, conventional contact seals are not feasible for micro-machining spindles. Noncontact seals are therefore necessary to reduce leakage flow from the turbine backplate into the spindle housing, and to prevent the ingress of debris/dust at the front/tool-end of the spindle during the cutting process. Off-the-shelf labyrinth seals for miniature shaft sizes are not widely available, so custom tooth-on-stator type labyrinth seals were designed for each end of the spindle and analysed using CFD. The 
seals for the initial prototype were designed with generous clearance to allow for significant vibration and other shaft displacements. The prototype seals had a radial clearance of $0.1 \mathrm{~mm}$, six teeth and a pitch and height of $0.5 \mathrm{~mm}$ and $1.1 \mathrm{~mm}$, respectively. The CFD results (Fig. 6) indicated that the seals reduced leakage flow by $30 \%$ in comparison to a simple annular passage of identical radial clearance and length.

Nevertheless, even with the seals a small mass flow was expected through the spindle. This will result in a positive air pressure in the spindle body which should aid the sealing of the tool-end. In addition, due to the proximity of the back (turbine-end) bearings to the turbine rotor backplate, it was expected they would operate at a lower temperature due to the cooling effect of the leakage flow. The compressed air leakage into the spindle body may necessitate more frequent replacement of the bearing grease.

\section{Spindle Development and Testing}

\subsection{Part Manufacturing and Spindle Assembly}

The turbine rotor, nozzle guide vanes and volute assembly were all milled from an aluminium alloy (6061-T6) on a 5 -axis machine tool (Fig. 7). While the turbine was designed to be manufactured from a magnesium alloy, this entailed higher initial setup costs due to the necessary fire precautions for magnesium machining. The prototype turbine had an outer diameter of $25 \mathrm{~mm}$, an inlet span of $1.9 \mathrm{~mm}$, and an axial length of $11.5 \mathrm{~mm}$ which included a hex drive for assembly (see "Appendix" for a cross-sectional view of turbine). An important manufacturing consideration is the blade-to-blade gap. To reduce machining time, a minimum gap of greater than $0.5 \mathrm{~mm}$ was used. In addition, a relatively large blade fillet radius of $0.35 \mathrm{~mm}$ was employed. The specified average surface roughness was $1.6 \mu \mathrm{m}(\mathrm{Ra})$.

For assembly, the turbine rotor was shrink fitted to the shaft. Since both aluminium and magnesium alloys have relatively low melting points, the level of interference between

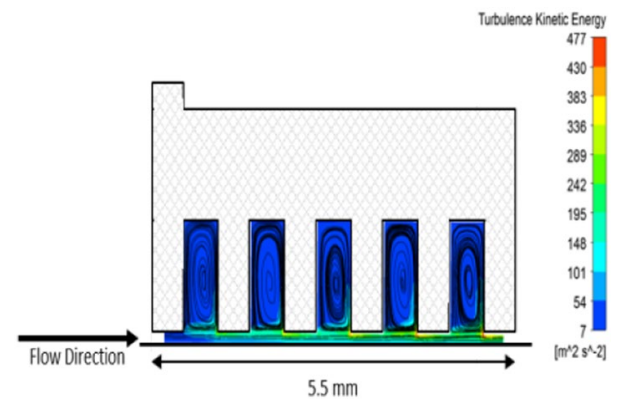

Fig. 6 CFD predicted turbulence in labyrinth seal (turbine end)
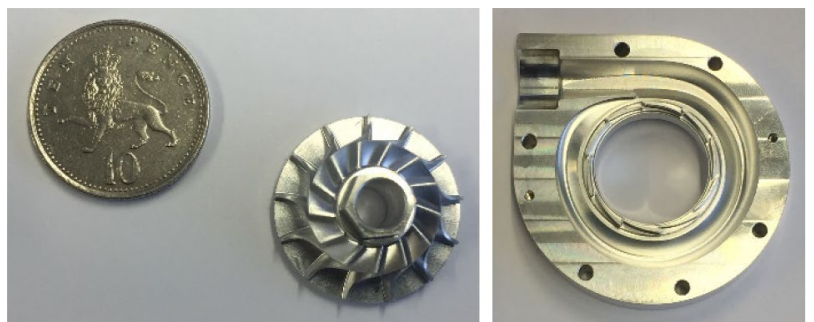

Fig. 7 Turbine rotor (left) and half-section of volute with NGV's (right)

the turbine rotor and the shaft is restricted by the temperature required to expand the rotor hub during assembly and, more critically, disassembly.

At such small sizes, the radial and axial clearance between the turbine rotor blades and shroud (volute casing wall) is of critical importance (Appendix Fig. 18). A relatively large constant clearance of $0.5 \mathrm{~mm}$ was employed for the initial prototype spindle to allow for any unforeseen motion errors. The nominal turbine backplate clearance was also $0.5 \mathrm{~mm}$ in case of significant thrust in either axial direction. To allow for further adjustment of the axial clearance between the rotor backplate and housing, a $0.2 \mathrm{~mm}$ thick stainless steel shim was custom manufactured. The final assembled prototype spindle and its components are shown in Fig. 8.

The total weight and volume of the prototype spindle was approximately $318 \mathrm{~g}$ and $100 \mathrm{~cm}^{3}$, respectively. The addition of a silencer, which would be required for a commercial spindle, would add approximately $25-35 \mathrm{~g}$ of weight



Fig. 8 Turbo-spindle components including assembly tools and fixtures (top), and assembled prototype (bottom) 
depending on the level of noise reduction e.g. $25 \mathrm{~dB}$ or $30 \mathrm{~dB}$. A static radial stiffness at the tool-holder nose of $0.65 \mathrm{~N} / \mu \mathrm{m}$ was measured using calibrated weights and a dial indicator.

It is clear from Fig. 9 that the volute casing adds significant weight to the spindle. In addition, to inertia savings, a smaller diameter turbine rotor allows for a smaller volute with reduced spindle weight. The use of a magnesium alloy material for the turbine rotor would further reduce overall (rotor assembly) polar inertia by around $30 \%$, which in turn would reduce the time-to-speed of the spindle. The weight reduction is negligible since the turbine rotor accounts for only a small fraction of the spindle weight. Further rotor inertia savings are possible by scalloping the back-face of the turbine rotor.

\subsection{Experimental Setup and Spindle Run-In}

To experimentally test the performance of the developed prototype turbo-spindle in terms of structural integrity, power output, energy efficiency, and time-to-speed, a number of test rigs were developed as shown in Fig. 10. The rotational speed of the spindle was measured with an optical sensor (Monarch Instruments ROLS-W). The air mass flowrate (CS Instruments VA420) and static pressure (SMC
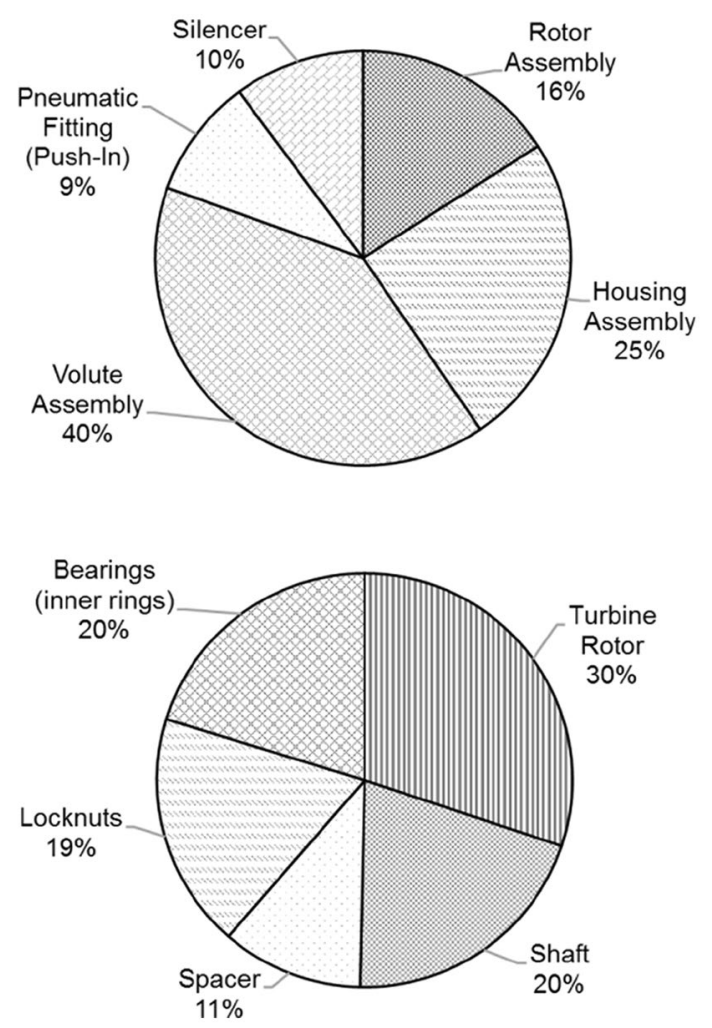

Fig. 9 Breakdown of turbo-spindle weight including silencer (top) and rotor inertia (bottom)

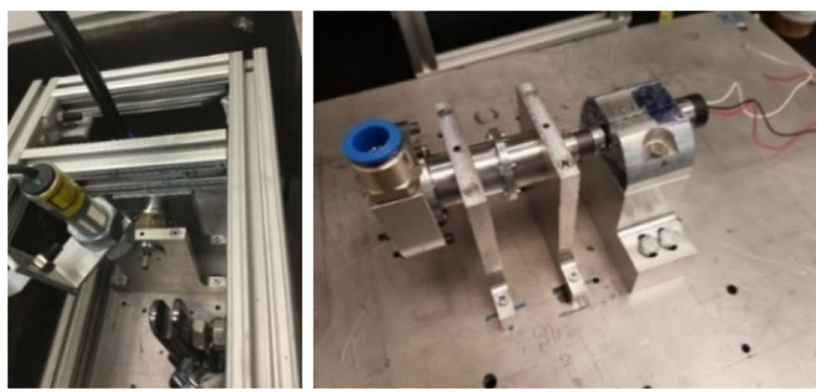

Fig. 10 Test stands for acceleration (left) and electric power measurement (right)

PSE530) were measured upstream of the spindle. The air temperature upstream of the spindle inlet and downstream of the turbine/spindle exhaust was measured using one T-type and three K-type thermocouples respectively. The spindle temperature was monitored using two J-type thermocouples placed on the housing body at the approximate locations of the front and rear bearings. An accelerometer (PCB Piezotronics 352A24) was used to monitor vibration on the housing assembly. The electrical current and voltage produced by an electric generator coupled to the prototype spindle were measured using a power meter (Yokogawa CW240). The voltage measurements were also verified using a separate oscilloscope (Tektronix TDS360). A summary of the range and accuracy of the sensors used for the experimental testing is shown in Table 3. A National Instruments data acquisition system (NI-6259) was used for recording the sensor output data and a sampling rate of at least $5 \mathrm{kHz}$ was employed to ensure no aliasing of the recorded data.

To evenly distribute the grease lubrication in the spindle bearings, the turbo-spindle was run for over $24 \mathrm{~h}$ prior to experimental testing of spindle acceleration and power output. To demonstrate the structural integrity of the rotor assembly,

Table 3 Sensor range and measurement accuracy

\begin{tabular}{llll}
\hline Measurand & Unit & Range & Accuracy \\
\hline Rotational speed & $\mathrm{rpm}$ & $1-250,000$ & $0.005 \%$ \\
Flowrate $^{\mathrm{a}}$ & $\mathrm{m}^{3} / \mathrm{h}$ & $0-170$ & $\pm 1.5 \% \mathrm{~m} . v$. \\
Pressure & $\mathrm{bar}$ & $0-10$ & $\pm 2 \% \mathrm{~F} . \mathrm{S}$. \\
Temperature $(\mathrm{J})$ & ${ }^{\circ} \mathrm{C}$ & -60 to 175 & $\pm 2.2{ }^{\circ} \mathrm{C}$ \\
Temperature $(\mathrm{T})$ & ${ }^{\circ} \mathrm{C}$ & -250 to 350 & $\pm 1{ }^{\circ} \mathrm{C}$ \\
Temperature $(\mathrm{K})$ & ${ }^{\circ} \mathrm{C}$ & -200 to 1250 & $\pm 2.2{ }^{\circ} \mathrm{C}$ \\
Electric voltage & $\mathrm{V}$ & $150-1000$ & $\pm 0.2 \% \mathrm{~m} . v$. \\
Electric current & $\mathrm{A}$ & $0-50$ & $\pm 3 \%$ \\
Vibration & $\mathrm{g}$ & $\pm 50 \mathrm{pk}$ & - \\
\hline
\end{tabular}

$p k$ Peak

${ }^{\text {a }}$ Normalised flowrate. Reference density according to ISO1217 standard atmospheric conditions $\left(1 \mathrm{bar}, 20^{\circ} \mathrm{C}\right)$ 
the turbo-spindle was also spun up to a maximum speed of $100,000 \mathrm{rpm}$. To conduct flowrate and power measurements at constant speed, the spindle was coupled to a small Brushless DC (BLDC) electric motor using a flexible bellows coupling. The spindle drives the BLDC motor, which acts as a generator. A range of resistor sizes from 120 to $15 \Omega$ (with $1 \%$ tolerance) were used to vary the electrical load and thus mechanical load on the generator and spindle at different speeds (Fig. 10).

\subsection{Experimental Methods}

The turbine power output was determined using two approaches. For the first method, the net power and torque were computed by accelerating the turbo-spindle to different speeds i.e. $70 \mathrm{k}, 80 \mathrm{k}, 90 \mathrm{k} \mathrm{rpm}$. The spindle torque and power were calculated from the known moment of inertia of the rotor assembly and the measured acceleration. Likewise, the frictional torque of the spindle bearings was estimated by switching off the turbine air supply when it was rotating at various speeds (corresponding to various inlet pressures) and measuring the deceleration. The torque produced by the turbine was then calculated by adding the spindle torque and the bearing frictional torque $\left(\tau_{\text {turbine }}=\tau_{\text {spindle }}+\tau_{\text {bearings }}\right)$.

For the second method, the turbo-spindle was coupled to an electric motor/generator that supplied a 3-phase Wye connected load(s). The electrical power output was determined by measuring the phase (and line) voltage amplitudes across the load resistors with a power meter. The efficiency of the electric generator was calculated by coupling the BLDC generator to an identical BLDC motor and measuring the input and output electrical power at various electrical loads and speeds. The output power was determined in the same manner as the turbospindle with generator setup. The input power to the motor was calculated based on the measured motor input current (on PWM controller/amplifier) and an estimated voltage. Since the supply voltage could not be measured directly with the PWM controlled BLDC motor, it was deduced based on the measured speed and motor speed constant. The motor speed constant is subject to an error of $\pm 10 \%$ which is one of the main sources of inaccuracy with this approach. As the BLDC motors were the same, the losses were assumed to be evenly distributed across both motors i.e. $\eta_{\text {motor }}=\eta_{\text {generator }}=\sqrt{ }\left(\eta_{\text {system }}\right)$.

The power output of the spindle and turbine was then determined using Eqs. 1 and 2, where the frictional power of the bearings was calculated using the deceleration test data:

$$
\begin{aligned}
P w_{\text {spindle }} & =\frac{P w_{\text {generator }}}{\eta_{\text {generator }}}, \\
P w_{\text {turbine }} & =P w_{\text {spindle }}+P w_{\text {bearings }} .
\end{aligned}
$$

In addition, for each resistor load, the air flowrate and supply pressure required to reach different speeds were recorded, which allowed for the creation of the turbo-spindle flow map. All experimental tests were repeated at least three times for repeatability.

The spindle and turbine efficiency were estimated by comparing the mechanical power output of the spindle and turbine respectively with the air power input (Eqs. 3 and 4). The test rig efficiency was computed by dividing the electrical power output of the generator by the air power input (Eq. 5):

$\eta_{\text {spindle }}=\frac{P w_{\text {spindle }}}{P w_{\text {air }}}=\frac{P w_{\text {spindle }}}{P_{a} \cdot \dot{V}_{a} \cdot \ln \frac{P_{u}}{P_{a}}}$,

$\eta_{\text {turbine }}=\frac{P w_{\text {turbine }}}{P w_{\text {air }}}=\frac{P w_{\text {turbine }}}{P_{a} \cdot \dot{V}_{a} \cdot \ln \frac{P_{u}}{P_{a}}}$,

$\eta_{\text {test_rig }}=\frac{P w_{\text {generator }}}{P w_{\text {air }}}$.

Finally, the potential cooling capacity available was calculated using Eq. 6 based on the measured flowrate and average measured exhaust temperature. Note, the calculated cooling capacity assumed the compressed air had been dried to a sufficient level to prevent water vapour condensation, and latent heat effects were therefore neglected:

$\dot{Q}_{\text {cooling }}=\dot{m} \cdot C_{p} \cdot \Delta T$.

\section{Turbine and Spindle Performance Results}

\subsection{Acceleration and Deceleration Tests}

Figure 11 shows the power output of the turbine and frictional power consumption of the spindle bearings over a range of speeds. The friction power of the spindle bearings is clearly quite significant, consuming over $40 \mathrm{~W}$ of power at $90,000 \mathrm{rpm}$. This is likely due to the large increase in bearing preload at high speeds. The CFD simulations

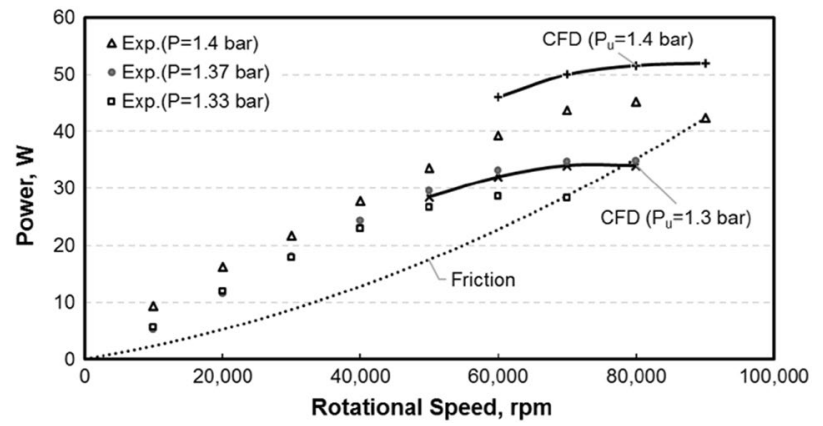

Fig. 11 Turbine power output and bearing frictional power load (measured and simulated) 
over-predict the turbine power output by $12-14 \%$ in comparison to the experimental measurements. It is important to note the experimental static pressure measurements are made upstream of the volute, inlet fitting and a small length of pneumatic tubing. The CFD predictions are based on a total pressure at the inlet to the stator nozzle guide vanes of the turbine stage. The exit pressure for the turbine (operating backpressure) is atmospheric air pressure for both the simulations and experiments i.e. 1.01 bar. The slow response time of the thermal mass based flowmeter means that it is not possible to accurately measure the transient air flow response to a step change in speed. Therefore, the acceleration based method does not allow for the calculation of the air power input and spindle efficiency.

\subsection{Electrical Power Tests}

The electrical power output of the generator and test system (spindle coupled to BLDC motor/generator) efficiency are shown in Fig. 12. The compressed air to electrical efficiency ranges from 5 to $20 \%$. The maximum rated efficiency of the BLDC motor/generator was 92\%. However, Fig. 13 demonstrates that for the range of tested electrical (and mechanical) loads, the motor was operating at a much-reduced efficiency in particular for the higher resistor measurements (low current, low torque). This was expected since the torque load was significantly less than the rated torque of the motor. Interestingly, the motor efficiency appears to reduce at
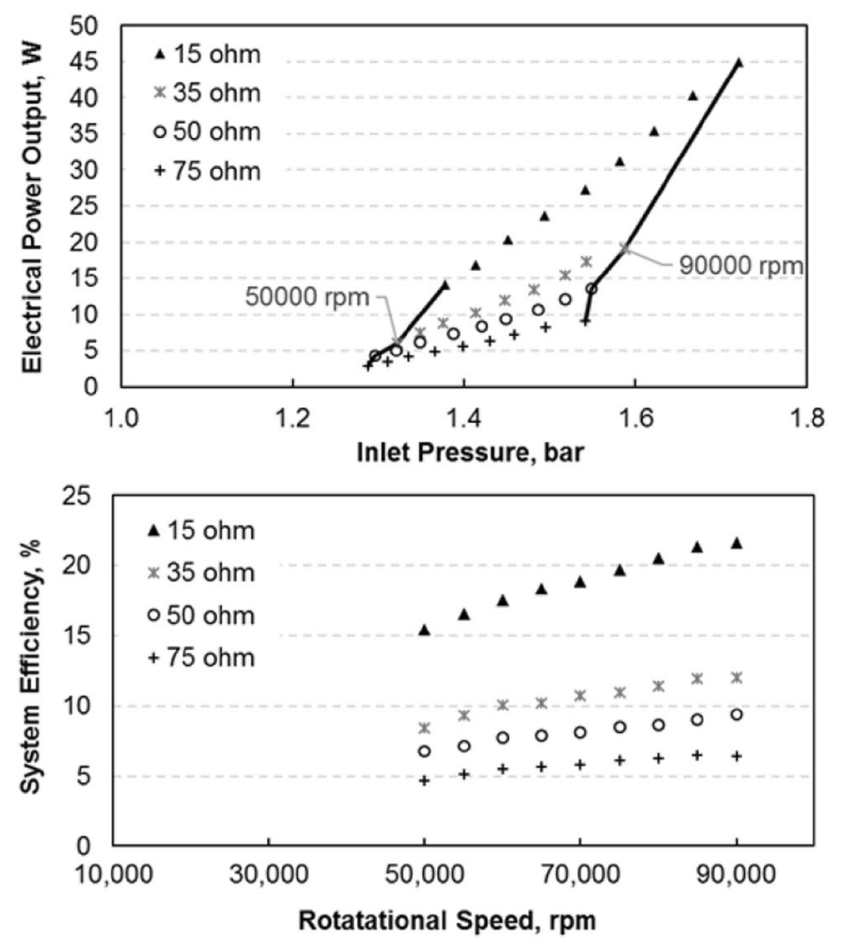

Fig. 12 Test rig electrical power output (top) and efficiency (bottom)



Fig. 13 BLDC motor/generator efficiency test setup (top) and measurements (bottom)

higher speeds (Fig. 13). This is likely due to operation at a higher supply voltage which causes a shift in the efficiency curve. BLDC motor efficiency varies with both supply voltage and PWM duty cycle. Due to vibration issues the BLDC motor coupled to BLDC generator could not be tested above $80,000 \mathrm{rpm}$.

The flow map for the prototype turbo-spindle is shown in Fig. 14. There is a good agreement between the simulated and measured data, with the difference in the range of 5-7\%. It is also clear from Fig. 14 that the turbine is operated in the subsonic flow region, and therefore has capacity to operate with higher power output and speed if required. According to the CFD simulations, the choke point occurs at an inlet pressure of around 3 bar (abs).

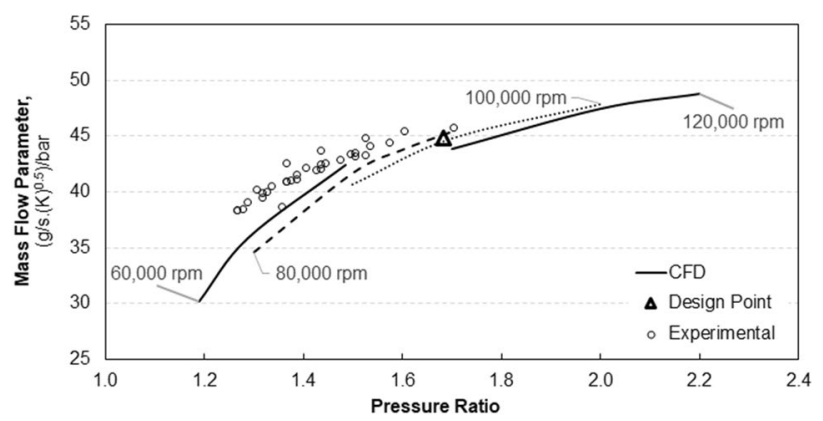

Fig. 14 Prototype turbo-spindle flow map (measured and simulated) 
The mechanical power output of the turbine is shown in Fig. 15. The prototype turbine reaches just under $100 \mathrm{~W}$ at $90,000 \mathrm{rpm}$. The highest turbine efficiency attained in the experiments was approximately $54 \%$.

To better illustrate the comparison of simulated and experimental results, the experimental measurements for mechanical power at selected speeds, and torque at selected pressure ratios, are shown in the lower part of Figs. 15 and 16, respectively. The CFD simulations over-predict the power output of the turbine by approximately $6-10 \%$ (compared to $12-14 \%$ for the acceleration method). However, it should be noted that the electrical power experimental method is quite sensitive to the efficiency of the BLDC motor/generator. Nonetheless, both Figs. 15 and 16 demonstrate that the CFD simulations predict the trend in power and torque output with reasonable accuracy. Due to the relatively small loads applied and the limited spindle speed, the prototype turbo-spindle did not reach its design operating point. Figure 16 demonstrates that the turbine should produce significantly higher torque and power at higher supply pressures.

\subsection{Cooling Capacity and Spindle Running Temperature}

The cooling power produced by the turbine at two electrical loads is shown in Fig. 17. The ambient temperature was
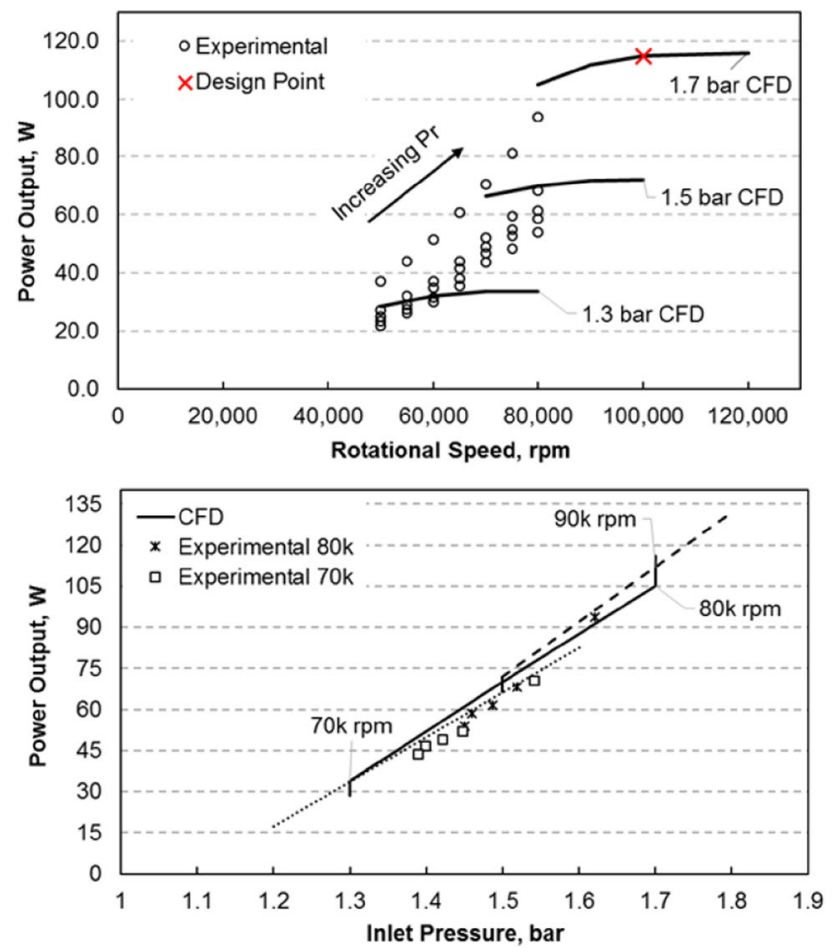

Fig. 15 Turbine power output at steady load (measured and simulated)

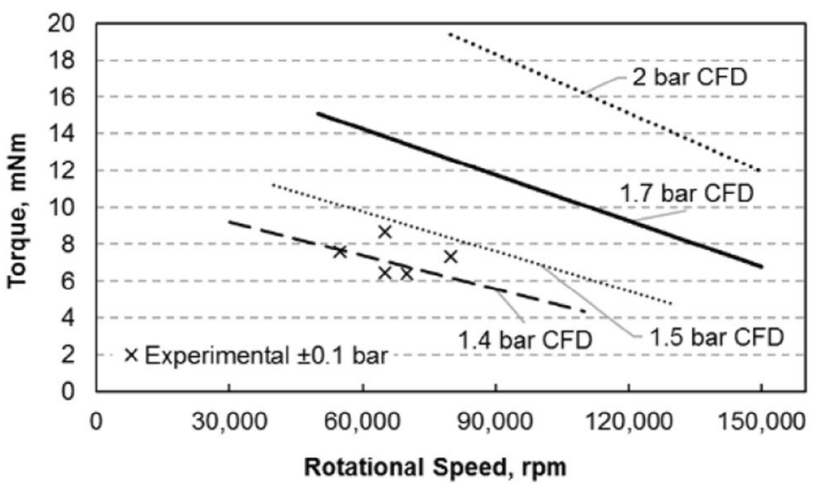

Fig. 16 Torque-speed curve for prototype turbine (measured and simulated)

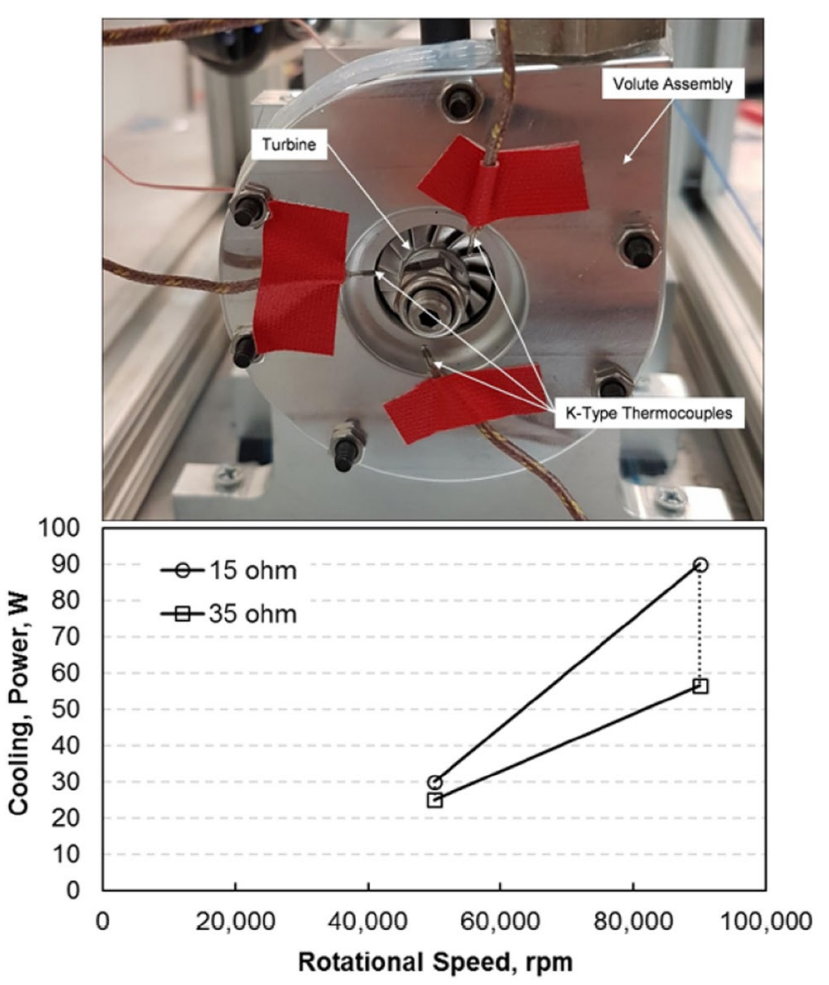

Fig. 17 Turbine exhaust temperature measurement (top) and cooling power with electrical loads (bottom)

$20{ }^{\circ} \mathrm{C}$. It can be seen in the figure that the prototype turbine produces a significant amount of cold energy, ranging from 25 to $90 \mathrm{~W}$ at an outlet temperature of $13{ }^{\circ} \mathrm{C}$ and $1{ }^{\circ} \mathrm{C}$ respectively. The utilisation of this exhaust air for cooling the cutting tool in a machining process (sometimes referred to as chilled air assisted machining [21, 22]) would further increase the energy efficiency of the turbo-spindle. The cold air for such applications would otherwise have to be generated by additional equipment such as vortex tubes or liquid nitrogen baths. In this manner, the machine tool spindle 
Table 4 Spindle housing steady state temperatures

\begin{tabular}{lll}
\hline Rotational speed $(\mathrm{rpm})$ & Temp. (front) $\left({ }^{\circ} \mathrm{C}\right)$ & $\begin{array}{l}\text { Temp. } \\
(\text { rear }) \\
\left({ }^{\circ} \mathrm{C}\right)\end{array}$ \\
\hline 50,000 & 25 & 22 \\
90,000 & 31 & 26 \\
\hline
\end{tabular}

would both remove material, and provide coolant for removing the heat generated by the material removal process.

The operating temperature of the spindle is shown in Table 4. As expected, the turbine-end bearing(s) operated at a lower temperature than the tool-end. This was likely due to compressed air leakage from the turbine into the spindle body and the fact that the rear/turbine-end bearing outer rings were allowed to float in the axial direction.

\section{Discussion}

A turbine efficiency of approximately $54 \%$, a turbo-spindle efficiency of $35 \%$ and a turbo-spindle power to weight of just under $0.2 \mathrm{~kW} / \mathrm{kg}$ have been achieved for the first prototype. However, given that the maximum power output has not been reached (the highest supply pressure used was only 1.7 bar), a spindle power-to-weight ratio of at least $0.7 \mathrm{~kW} /$ $\mathrm{kg}$ is deemed feasible. For example, the CFD simulations predict a turbine power output of $314 \mathrm{~W}$ is achievable at a rotational speed of $120,000 \mathrm{rpm}$ and a supply pressure of 2.5 bar. Taking into consideration bearing friction, this would translate to a net spindle power output of around $250 \mathrm{~W}$.

The maximum power output and efficiency of the turbine has yet to be demonstrated as it requires both higher speed spindle operation and a larger mechanical load. A larger electrical current load would enable spindle testing in the higher power output range. This could be facilitated using resistors of less than $15 \Omega$ rating. In addition, a torque-meter would enable more accurate mechanical power measurements at steady loads. The lower measured values of turbine power output and efficiency in comparison to the CFD simulations are attributed to: (1) blockage at the turbine outlet caused by the locknut, (2) internal leakage over the NGV's due to tolerance stack in the volute assembly, (3) leakage around the turbine backplate due to the large axial clearance. The first cause of efficiency loss was due to an oversized locknut and can easily be eliminated. Turbine stage clearances could also be significantly reduced in a future model.

Nevertheless, the energy efficiency of the prototype radial-inflow/axial-outflow turbine compares favourably with existing commercial options (Table 5). Previous turbines utilised for machining spindles have included tangential-inflow
Table 5 Comparison of prototype and commercial micro-machining turbo-spindle efficiency

\begin{tabular}{lll}
\hline & $\begin{array}{l}\text { Range of commercial effi- } \\
\text { ciency }(\%)\end{array}$ & $\begin{array}{l}\text { Prototype } \\
\text { efficiency } \\
(\%)\end{array}$ \\
\hline Turbo-spindle & $10-25$ & 35 \\
Turbine & $15-30$ & 54 \\
\hline
\end{tabular}

(Pelton) turbines, cantilever radial turbines, viscous turbines, and axial turbines. For the specific operating conditions of micro-machining, such turbines suffer from additional losses due to partial admission, flow turning, and tip leakage. Note, the efficiency of commercial turbo-spindles in Table 5 is based on the nominal datasheet specifications of both speed increasing turbo-spindles ('spindle speeders') and air bearing turbo-spindles. The datasheet information for spindle speeders enables a calculation of overall spindle efficiency. In contrast, the datasheet information for air bearing turbospindles allows for an approximation of individual turbine efficiency. This is because the parasitic power consumption of air bearings is significantly reduced in comparison to the rolling bearings in spindle speeders.

Further efficiency improvements with the radial-inflow/ axial-outflow turbine design are also possible. Based on a tolerance stack and error motion analysis, a turbine rotor clearance of $0.1 \mathrm{~mm}$ is considered viable due to the low thermal expansion and vibratory motion i.e. after balancing. CFD simulations indicate a $5 \%$ efficiency gain at the design point for the turbine with the reduced clearance. Furthermore, the low blade speed and thermal load offer further opportunities for improving the efficiency of the turbine rotor e.g. by using blade sweep at the inlet. Both options for improving turbine efficiency (reduced clearance and swept rotor) entail higher manufacturing cost. Further time-to-speed improvements are also possible with the use of a magnesium alloy material for the turbine stage. However, the relatively low corrosion resistance of such materials would require sufficient upstream drying of the compressed air supply and/or additional surface treatment (e.g. anodisation) to prevent and/or protect against potential corrosion. The low temperatures produced by the expansion of compressed air in the turbine may otherwise cause condensation of water vapour and subsequent corrosion and material deterioration in service. In addition, the low melting point of magnesium alloys may require an alternative assembly approach to shrink fitting, for mounting the turbine rotor to the spindle shaft e.g. screw on.

Due to shaft manufacturing out-of-tolerances, the radial run-out of the prototype turbo-spindle is unacceptable for machining purposes at present. In addition, the rotor assembly requires balancing for extended operation at high speeds i.e. higher than $90,000 \mathrm{rpm}$. It is also clear that the UHS 
prototype spindle mechanical power output is significantly reduced due to the large bearing torque load at high speed. For example, approximately $40 \%$ of the turbine power is consumed by the angular contact bearings at $90,000 \mathrm{rpm}$. A single spring loaded angular contact bearing could replace the current bearing set located at the turbine-end, which would help reduce the parasitic power consumption of the bearings and reduce heat generation. Further increases in spindle speed could be achieved by moving to an oil-air lubrication system for the ball bearings or moving to a fully pneumatic spindle design i.e. air turbine drive with air bearings.

Finally, the utilisation of thermal energy in the turbine exhaust would further improve the overall energy efficiency of the turbo-spindle. If the cold air exhaust from the spindle's drive turbine was used directly for cooling in the machining process, significant energy savings would be achieved by avoiding the use of a vortex tube, air (vapourcompression) chiller, cryogenic bath, etc. However, for actual implementation the turbine would need to operate with a higher backpressure to (1) allow for downstream pressure drop and (2) allow for smaller diameter downstream tubing to deliver the cold air to the point of use. Given that the spindle is located at the cutting zone, the length of tubing and therefore required backpressure is not likely excessive. In addition, insulation would be required for the exhaust tubing, but this is no different to delivery from other cold energy producing devices.

\section{Conclusions}

A first-generation prototype turbo-spindle has been developed in this work and provides an initial proof of principle that significant gains in turbine and spindle efficiency are possible for micro-machining applications, by utilising full admission radial-inflow/axial-outflow turbines with 3D blade profiles. The prototype turbo-spindle has been tested to a maximum speed of $100,000 \mathrm{rpm}$, and achieved a maximum turbine and spindle energy efficiency of $54 \%$ and $35 \%$, respectively. The level of efficiency attained represents a 40-250\% improvement in comparison to the efficiency of commercially available manufacturing turbo-spindles. The gains in spindle power density are of similar magnitude. An important point to emphasise is that increasing spindle energy efficiency not only offers energy cost savings, it enables a reduction in non-cutting time and an extension of cutting speed range.

To realise a full proof of concept, the current prototype requires a new shaft and full balancing of the rotor assembly. This will allow for future analysis of the spindle's performance in terms of dynamic run-out, vibration modes and critical speeds, and ultimately machining quality i.e. dimensional accuracy and surface finish.

Acknowledgements This project was funded by the European Union Seventh Framework Programme [FP7/2013] under grant agreement no. 625735. The authors would like to thank Prof. Masakazu Soshi (UC Davis) for his technical guidance early in the project.

\section{Compliance with Ethical Standards}

Conflict of interest On behalf of all authors, the corresponding author states that there is no conflict of interest.

Open Access This article is distributed under the terms of the Creative Commons Attribution 4.0 International License (http://creativeco mmons.org/licenses/by/4.0/), which permits unrestricted use, distribution, and reproduction in any medium, provided you give appropriate credit to the original author(s) and the source, provide a link to the Creative Commons license, and indicate if changes were made.

\section{Appendix}

See Fig. 18.



Fig. 18 Meridional view of radial-inflow/axial-outflow turbine including preliminary design parameters 


\section{References}

1. Schubert, A., Harpaz, O., Books, B. (2013) HPC for improved efficiency on standard machine tools by using new fluid-drive spindles. In Global conference for sustainable manufacturing (GCSM), Berlin, Germany.

2. Li, W., Zhou, Z. X., \& Xiao, H. (2015). Design and evaluation of a high-speed and precision microspindle. The International Journal of Advanced Manufacturing Technology, 78(5-8), 997-1004.

3. Li, W., Zhou, Z. X., Huang, X. M., et al. (2014). Development of a high-speed and precision micro-spindle for micro-cutting. International Journal of Precision Engineering and Manufacturing, 15(11), 2375-2383.

4. Sung, H. (2007) High-speed fluid bearing micro-spindles for meso-scale machine tools (mMTs). PhD Dissertation, Northwestern University.

5. Jahanmir, S., Ren, Z., \& Heshmat, H. (2010). Design and evaluation of an ultrahigh speed micro-machining spindle. Machining Science and Technology, 14(2), 224-243.

6. Aurich, J. C., Müller, C., \& Walk, M. (2013). High-frequency tool-spindle for multifunctional, replaceable rotor-modules. Production Engineering, 7(5), 555-560.

7. Park, J. K., Kyung, J. H., Shin, W. C., et al. (2012). A magnetically suspended miniature spindle and its application for tool orbit control. International Journal of Precision Engineering and Manufacturing, 13(9), 1601-1607.

8. Knapp, B., \& Arneson, D. (2014) Dynamic characterization of a micro-machining spindle. In international conference on micromachining (ICOMM), Singapore.

9. Creighton, E., Honegger, A., \& Tulsian, A. (2010). Analysis of thermal errors in a high-speed micro-milling spindle. International Journal of Machine Tools and Manufacture, 50(4), 386-393.

10. Anandan, K. P., \& Ozdoganlar, O. B. (2013). Analysis of error motions of ultra-high-speed (UHS) micromachining spindles. International Journal of Machine Tools and Manufacture, 70, $1-14$.

11. Bediz, B., Arda Gozen, B., \& Korkmaz, E. (2014). Dynamics of ultra-high-speed (UHS) spindles used for micromachining. International Journal of Machine Tools and Manufacture, 87, 27-38.

12. Zhang, G., \& Ehmann, K. (2015). Dynamic design methodology of high speed micro-spindles for micro/meso-scale machine tools. The International Journal of Advanced Manufacturing Technology, 76(1-4), 229-246.

13. Shin, W., Ro, S., \& Park, H. (2009). Development of a micro/ meso-tool clamp using a shape memory alloy for applications in micro-spindle units. International Journal of Machine Tools and Manufacture, 49(7), 579-585.

14. Harris, P., Linke, B., \& Spence, S. (2015). An energy analysis of electric and pneumatic ultra-high speed machine tool spindles. Procedia CIRP, 29, 239-244.

15. Jackson, M. J., Robinson, G. M., \& Hyde, L. J. (2007). Design and manufacture of high-speed spindles for dry micromachining applications. International Journal of Nanomanufacturing, 1(5), 641-656.

16. Müller, C., Reichenbach, I. G., \& Aurich, J. C. (2014) Design and numerical simulation of an air turbine for a high frequency tool spindle. In International conference on micromachining (ICOMM), Singapore.

17. Delhaes, G. M. J., van Beek, A., \& van Ostayen, R. A. J. (2009). The viscous driven aerostatic supported high-speed spindle. Tribology International, 42(11), 1550-1557.

18. Wardle, F. (2015). Ultra-Precision Bearings. Oxford: Woodhead Publishing.

19. Moustapha, H., Zelesky, M., \& Baines, N. (2003). Axial and Radial Turbines. Wilder: Concepts ETI Inc.
20. Harris, P., Linke, B., \& Spence, S. (2016). A numerical investigation of a miniature pneumatic spindle turbine. Proceedings of the Bath/ASME symposium on fluid power and motion control.

21. Rahman, M., Kumar, A. S., Salam, M.-U., \& Ling, M. S. (2013). Effect of chilled air on machining performance in end milling. The International Journal of Advanced Manufacturing Technology, 21(10-11), 787-795.

22. Su, Y., He, N., Li, L., et al. (2007). Refrigerated cooling air cutting of difficult-to-cut materials. International Journal of Machine Tools and Manufacture, 47(6), 927-933.

Publisher's Note Springer Nature remains neutral with regard to jurisdictional claims in published maps and institutional affiliations.

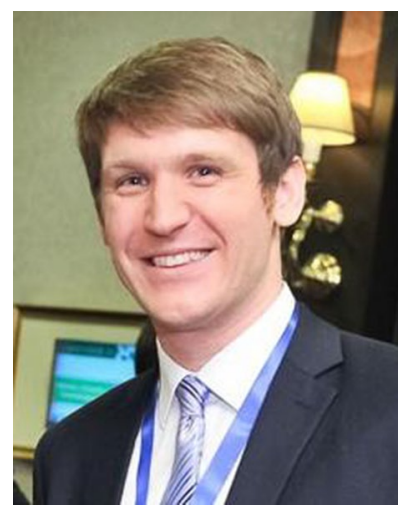

Paul Harris is currently a senior mechanical engineer with Brayton Energy in the USA. He previously worked as a Marie Curie Postdoctoral Research Fellow at Queen's University Belfast (UK), and at the University of California at Davis (USA). He graduated from Trinity College Dublin (Ireland) with a BSc in manufacturing engineering and a $\mathrm{PhD}$ in mechanical engineering, in 2007 and 2011, respectively. $\mathrm{He}$ is a member of the American Society for Mechanical Engineers (ASME).

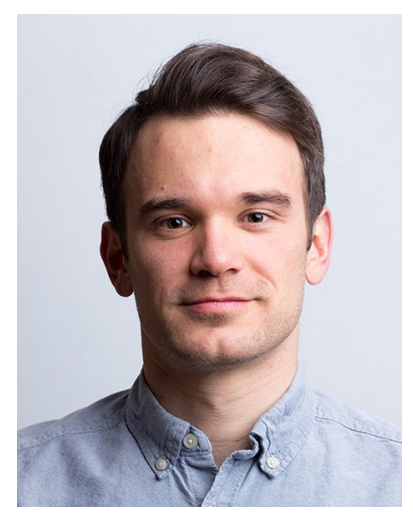

Michael Wintterer is currently a consulting engineer at StreetScooter Research $\mathrm{GmbH}$ in Munich, Germany. He graduated from RWTH Aachen University (Germany) with a BSc and MSc in business administration and mechanical engineering in 2016 and 2018 , respectively. He was a visiting student at the University of California, Davis in 2017.

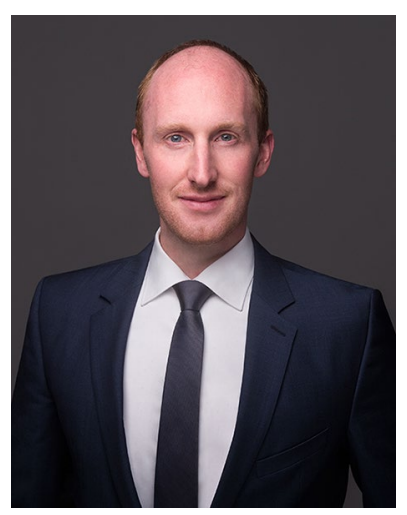

David Jasper is currently a senior project engineer at NEA $X$ $\mathrm{GmbH}$ in Aachen, Germany. He graduated from RWTH Aachen University (Germany) with a Diplom (Dipl.-Ing.) and a $\mathrm{PhD}$ in mechanical engineering in 2011 and 2018, respectively, and previously worked as a research associate at the Laboratory for Machine Tools and Production Engineering (WZL) of RWTH Aachen University. 


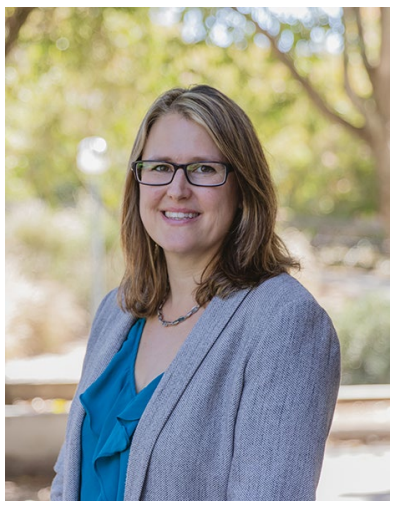

Barbara Linke is a faculty member of Mechanical and Aerospace Engineering at the University of California, Davis. She completed her Diplom (2002), doctorate (2007), and habilitation (2015) at the RWTH Aachen University, Germany, and worked as post-doc with Profs. Fritz Klocke and David Dornfeld. Her research interests include sustainable manufacturing, abrasive machining technologies, part quality, smart and data-driven manufacturing, among others. She has published over 70 peer-reviewed papers, authored two books, edited a book and a proceedings, and is an active member of ASME MED and SME. Barbara S. Linke received several awards, including the F.W. Taylor Medal of the CIRP in 2009, the Outstanding Young Manufacturing Engineer award of the SME in 2013, and the UC Davis College of Engineering Outstanding Junior Faculty Award in 2018.

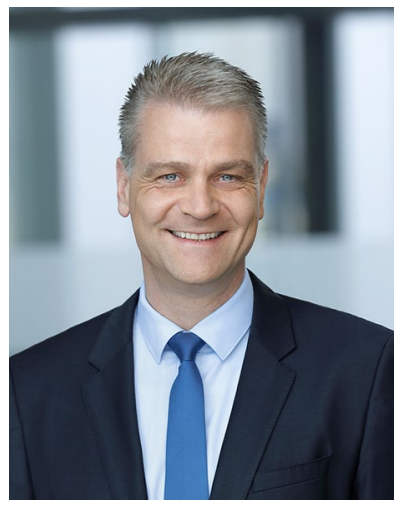

Christian Brecher is the Ordinary Professor (Since January 1, 2004) for Machine Tools at the Laboratory for Machine Tools and Production Engineering (WZL) of the RWTH Aachen as well as the Director of the Department for Production Machines at the Fraunhofer Institute for Production Technology IPT. Further, he is CEO of the Cluster of Excellence "Integrative Production Technology for High-Wage Countries" that is funded by the German Research Foundation (DFG). Together with his colleague Prof. Hopmann, he is also responsible for the Aachen Center for Integrative Lightweight Production (AZL) since 2012. After finishing his academic studies in mechanical engineering, he started his professional career first as a research assistant and later as a team leader in the department for machine investigation and evaluation at the WZL. From 1999 to April 2001, he was responsible for the department of machine tools in his capacity as a senior engineer. After a short spell as a consultant in the aviation industry, Professor Brecher was appointed in August 2001 as the Director for Development at the DS Technologie Werkzeugmaschinenbau GmbH, Mönchengladbach, where he was responsible for construction and development until December 2003. Prof. Brecher has received numerous honours and awards including the Springorum Commemorative Coin, the Borchers Medal of the RWTH Aachen, the Scholarship Award of the Association of German Tool Manufacturers (Verein Deutscher Werkzeugmaschinenfabriken VDW) and the Otto Kienzle Memorial Coin of the Scientific Society for Production Technology (Wissenschaftliche Gesellschaft für Produktionstechnik WGP). From 2015 to 2017 he was for a period of 3 years chairman of the scientific group for machines of CIRP, the International Academy for Production Engineering. From 2015 to 2017, Professor Brecher became the acting Head of Institute at the Fraunhofer Institute for Production Technology IPT and in January 2018 he accepted the permanent position of Head of Institute.

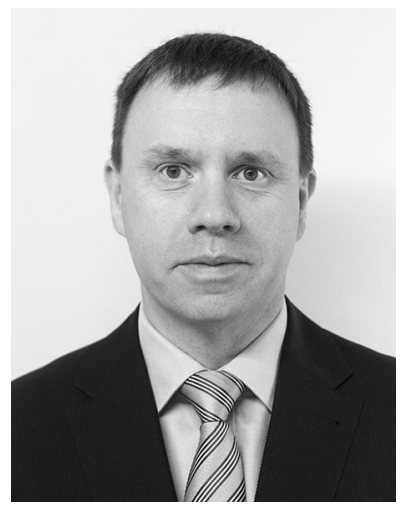

Stephen Spence received his bachelor's degree and his $\mathrm{PhD}$ from Queen's University Belfast. He has been working in the area of radial turbomachinery for 25 years with various industrial collaborators, particularly international turbocharger manufacturers. Prof Spence is a past Chair of the IGTI Turbomachinery Committee and Associate Editor of the ASME Journal of Turbomachinery. He has also served on the technical organizing committee for the IMechE Turbocharger Conference and the

European Turbomachinery Conference. He leads the turbomachinery research group at Queen's University Belfast with ten $\mathrm{PhD}$ students and research fellows. 